\title{
Day-to-day variation of pre-reversal enhancement in the equatorial ionosphere based on GAIA model simulations
}

\author{
Priyanka Ghosh ${ }^{1 *} \mathbb{0}$, Yuichi Otsuka', Sivakandan Mani ${ }^{1}$ and Hiroyuki Shinagawa ${ }^{2}$
}

\begin{abstract}
Using a whole atmosphere-ionosphere coupled model GAIA (ground-to-topside model of atmosphere and ionosphere), we have investigated which parameters mainly control day-to-day variation of vertical plasma drift at the evening terminator over magnetic equator, so-called pre-reversal enhancement (PRE). Day-to-day variations of the peak PRE are compared with those of electron density, eastward current density and eastward neutral wind in the $\mathrm{E}$ - and F-region over Chumphon ( $10.7^{\circ} \mathrm{N}, 99.4^{\circ} \mathrm{E} ; 0.86^{\circ} \mathrm{N}$ magnetic latitude), Thailand during equinoctial months in 2011-2013. Eastward neutral wind in the F-region shows positive correlation with peak PRE, indicating that the F-region winds control the peak PRE through the mechanisms of the F-region dynamo (including E-and F-region coupling processes). Daytime eastward electric current at an altitude of $110 \mathrm{~km}$, corresponding to equatorial electro jet (EEJ), is also positively correlated with the peak PRE. Correlation between the EEJ and PRE is the largest at $1700 \mathrm{LT}$, approximately $1.5 \mathrm{~h}$ prior to the peak PRE.
\end{abstract}

Keywords: Pre-reversal enhancement, Eastward neutral wind, Eastward current density, Electron density, GAIA

\section{Introduction}

Equatorial plasma bubble (EPB) is characterized by localized plasma density depletion in the ionosphere, and are well-known due to their unique nature and adverse effects on communication and navigation systems. The Rayleigh-Taylor instability (RTI) is known to be the mechanism of EPB generation (Sultan 1996). Pre-reversal enhancement (PRE) is an enhancement of the vertical $\mathrm{E} \times \mathrm{B}$ drift due to the eastward electric field at the evening terminator at the magnetic equator. The eastward electric field strengthens before its reversal to westward direction post-sunset. PRE is believed to be one of the main controlling factors for the generation of EPB (Abdu 2001). There have been many studies in the past to show the connection of the PRE on the generation of EPB using ground-based and satellite observations (Abadi et al.

\footnotetext{
*Correspondence: iam.priyankaghosh@gmail.com

${ }^{1}$ Institute for Space-Earth Environmental Research, Nagoya University,

Nagoya 464-8601, Japan

Full list of author information is available at the end of the article
}

2015; Dabas et al. 2003; Huang and Hairston 2015; Tulasi Ram et al. 2006). However, mechanisms controlling dayto-day variation of the EPB occurrence are still unknown although it is important for the ionospheric community. Abadi et al. (2015) established that the magnitude of PRE governs the latitudinal extension of EPB along with the peak value of virtual height $\left(h^{\prime} F\right)$ during the developmental phase of EPB. Previous studies revealed that the daytime $\mathrm{E} \times \mathrm{B}$ drift and Equatorial Electro Jet (EEJ) have good positive correlation with the EPB generation (Dabas et al. 2003; Tulasi Ram et al. 2006).

Abdu et al. (1983) found that the onset of Equatorial Spread-F (ESF) is directly correlated with PRE peak during the southern summer solstice and equinoctial months in the equatorial ionosphere over Fortaleza. They found strong dependence of PRE and ESF intensity with solar flux index (F10.7) during the equinoctial months of solar maximum (mainly for strong ESF cases). Recently, Huang (2018) reported that PRE and ESF occurrence are linearly correlated. They found that the probability of occurrence of ESF is very less when peak PRE is negative, increases 
largely when peak PRE is $0-40 \mathrm{~ms}^{-1}$ and becomes $80 \%$ or higher above the threshold value of $40 \mathrm{~ms}^{-1}$. These studies reveal that plasma bubble occurrence largely depends on magnitude of PRE although various factors affect it (Abdu 2001). Uemoto et al. (2010) carried out the ionosonde and magnetometer observations over Chumphon and Phuket, respectively, during November 2007 to October 2008 to study the link among PRE, EEJ and ESF onset. They found that the increase in the virtual height ( $h$ 'F) of bottomside F-layer and EEJ strength are interconnected with the generation of ESF.

Fesen et al. (2000) simulated PRE using National Center for Atmospheric Research thermosphere/ionosphere/ electrodynamic general circulation model (TIEGCM) and reported that electron density in the E-region is one of the most vital parameter to produce PRE. The E-region electron densities $\geq 10^{4} \mathrm{~cm}^{-3}$ inhibit PRE development by 'short-circuiting' the F-region dynamo. Based on NCAR Whole Atmosphere Community Climate Model with thermosphere/ionosphere extension (WACCM-X) simulations, Liu (2020) reported that day-to-day variation of PRE is affected by the large-scale day-to-day variability of the lower atmosphere, through E-region in the summer hemisphere, at the mid-latitudes. Recently, Shinagawa et al. (2018) have shown that daily and seasonal variations of the RTI growth rate simulated by the Ground-to-topside model of Atmosphere-ionosphere for Aeronomy (GAIA) are consistent with those of EPB observed by GPS scintillation and VHF radar. However, mechanisms controlling the day-to-day variation of PRE have not been investigated well. Using GAIA, in the present study, an attempt is made to investigate mechanisms controlling the day-to-day variation of PRE. This study could contribute to a goal of forecasting EPB before its actual incidence.

\section{Data and instrumentation}

In the present study, a whole atmosphere-ionosphere coupled model, GAIA consisting of three models combining an ionosphere model, a neutral atmosphere model, and an ionospheric electrodynamic model (Jin et al. 2011; Shinagawa et al. 2018), is used to investigate day-to-day variation of plasma density, neutral winds, and electric current in the ionosphere over magnetic equator at a location of $\left(10^{\circ} \mathrm{N}, 100^{\circ} \mathrm{E}\right)$, which is close to Chumphon $\left(10.7^{\circ} \mathrm{N}, 99.4^{\circ} \mathrm{E}\right.$; $0.86^{\circ} \mathrm{N}$ magnetic latitude) in Thailand. The longitudinal and latitudinal grid spacing in the ionospheric model is 2.5 and 2.0 degrees, respectively. The vertical spacing is $10 \mathrm{~km}$ below an altitude of $600 \mathrm{~km}$. Temporal resolution of the output data used in this study is $30 \mathrm{~min}$. The present GAIA simulation does not include the geomagnetically disturbed condition.

The vertical component of plasma drift due to the zonal component of the electric field at the magnetic equator, corresponding to PRE, is derived from the electric field and magnetic field data (around 1600-0000 LT) (local time) during the equinoctial months March, April, September and October of 2011-2013. The period 20112013 is chosen as it represents the high solar activity period when the occurrence rate of equatorial plasma bubble will be high. It is to be noted that day number 60-90 (61-91) corresponds to March, 91-120 (92-121) corresponds to April, 244-273 (245-274) corresponds to September, 274-304 (275-305) corresponds to October for the year 2011 and 2013 (2012). Figure 1 shows the day-to-day variations of upward $\mathrm{E} \times \mathrm{B}$ drift velocity with

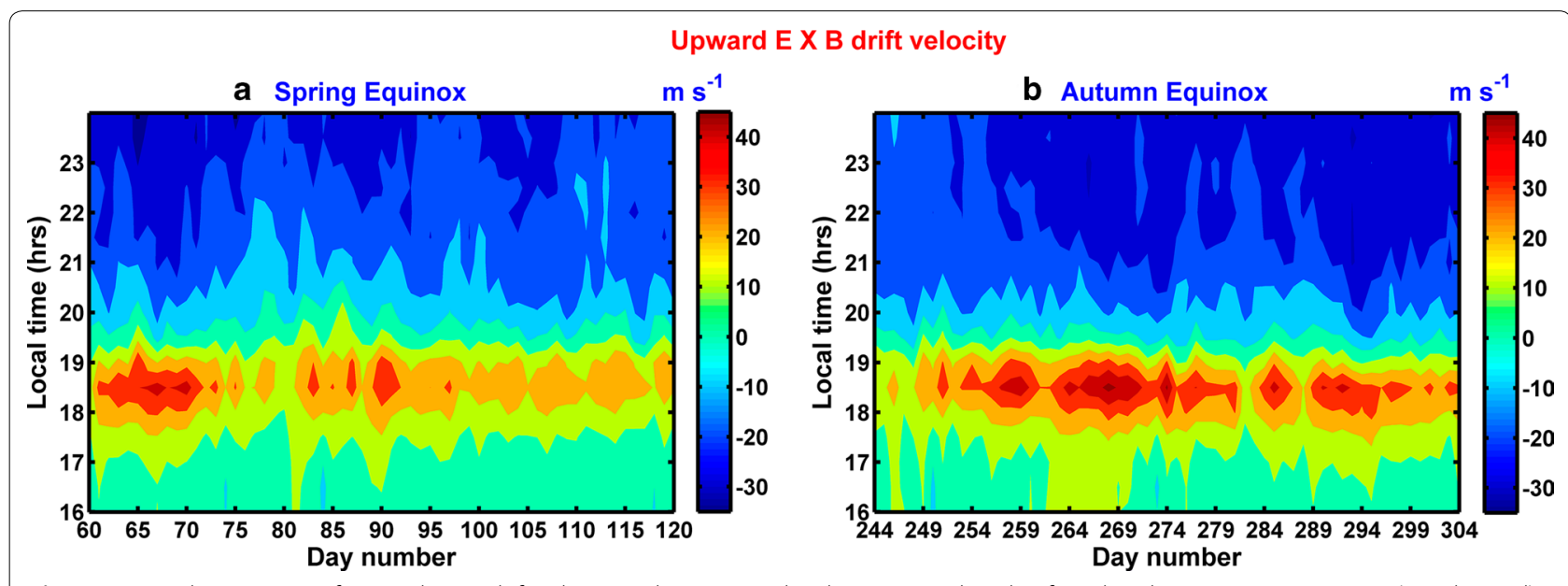

Fig. 1 Day-to-day variation of upward $E \times B$ drift velocity with respect to local time at an altitude of $300 \mathrm{~km}$ during a spring equinox (March-April) and $\mathbf{b}$ autumn equinox (September-October) of 2011 over ( $10^{\circ} \mathrm{N}, 100^{\circ} \mathrm{E}$; GAIA co-ordinates) near Chumphon in Thailand 
respect to local time at an altitude of $300 \mathrm{~km}$ at magnetic equator $\left(10^{\circ} \mathrm{N}, 100^{\circ} \mathrm{E}\right)$ near Chumphon in Thailand during (a) spring equinox (March-April) and (b) autumn equinox (September-October) of 2011. It is clearly visible that upward drift velocity enhances during 1800-1900 LT and reaches a peak around 1830 LT. This enhancement of the upward drift velocity corresponds to PRE. In this study, a peak value of PRE between 1830 and 1900 LT is mentioned as peak PRE during both the autumn and spring months irrespective of the sunset time. In the figure, day-to-day variation can be seen in magnitude of the peak PRE. The peak PRE exceeds $30 \mathrm{~ms}^{-1}$ during a period of day-of-year between 62 and 72, but were intermittently smaller than $10 \mathrm{~ms}^{-1}$ during a period of day-ofyear between 74 and 81 .

\section{Results}

Figure 2 shows the day-to-day variation of the peak PRE (magenta line) with $(\mathrm{a}, \mathrm{b})$ electron density, $(\mathrm{c}, \mathrm{d})$ eastward current density, and (e, f) eastward neutral wind at the time when the PRE reached a peak (around 1830-1900 LT) during (top) March-April and (bottom) SeptemberOctober of the year 2012 over $\left(10^{\circ} \mathrm{N}, 100^{\circ} \mathrm{E}\right.$; GAIA coordinates) near Chumphon in Thailand. The horizontal axis depicts the day number of the year. The day number 61-91 corresponds to March and day number 92-121 corresponds to April. The electron density peak $\left(\mathrm{F}_{2}\right.$ peak) exists at an altitude between 350 and $550 \mathrm{~km}$, and varies day by day. The $F_{2}$ peak is elevated to higher altitudes by PRE around evening terminator. The electron density in the E-region is quite smaller than in the F-region because the E-region plasma disappears due to rapid recombination soon after the solar extreme ultraviolet (EUV) radiation ceases. The rapid recombination of the plasma also makes a steep gradient of the electron density at the bottomside of the F-layer. Day-to-day variation in the altitude of bottomside F-layer is also seen. From comparison with the peak PRE, it is found that the $F_{2}$ peak and bottomside altitudes ascend and the electron density at the $F_{2}$ peak altitude decreases when the peak PRE is intense (Fig. 2a, b). In Fig. 2c, d, eastward electric current is shown. The eastward current density is enhanced at an altitude of $110-120 \mathrm{~km}$. This intense current density corresponds to EEJ. The intensity of EEJ varies day by day, and its day-to-day variation ranges between 0.05 and 0.12 $\mathrm{Am}^{-2}$ approximately. Intensification in the eastward current density coincides with enhancement of the peak in PRE, indicating positive correlation between peak PRE and current density on most of the days except for day numbers 68, 275, 284, 294 and 301. As shown in Fig. 2e, $\mathrm{f}$, the neutral wind is eastward in the F-region and westward in the altitude range between 120 and $200 \mathrm{~km}$. Dayto-day variation of the eastward wind in the F-region ranges from 50 to $100 \mathrm{~ms}^{-1}$, and displays distinct positive correlation with peak PRE. When the PRE is weak, the neutral wind weakens and correlation between the peak PRE and E-region neutral wind is not discernible. On few days, the positive correlation is not clearly seen (such as day numbers $69,83,88,115,248,254,266-271$ and 281) which may lead to weak positive correlation.

We have investigated quantitatively correlation of dayto-day variation of the PRE with that of the electron density, eastward current density and eastward neutral wind at the time when the peak PRE occurs. Figure 3 displays

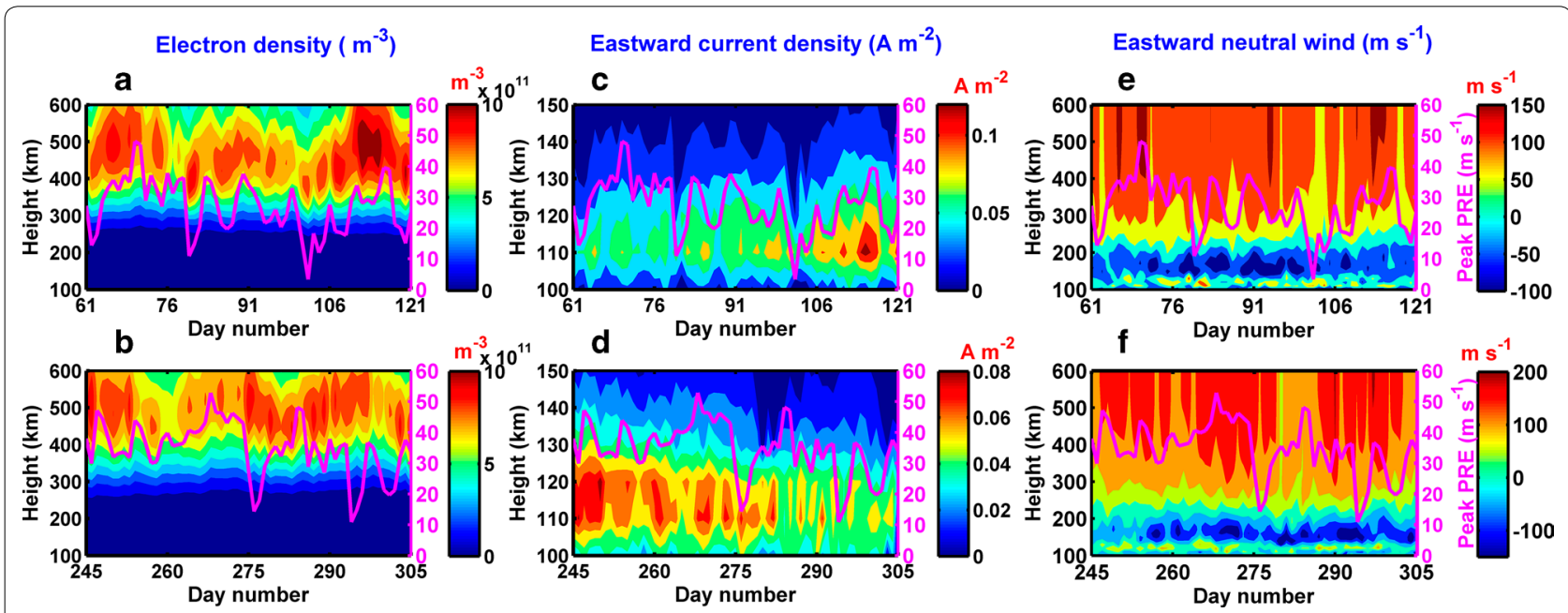

Fig. 2 Day-to-day variations of the peak PRE (magenta line) and $\mathbf{a}, \mathbf{b}$ electron density, $\mathbf{c}, \mathbf{d}$ eastward current density, and $\mathbf{e}, \mathbf{f}$ eastward neutral wind at the time when the PRE reached a peak during (top) March-April and (bottom) September-October in 2012 over $\left(10^{\circ} \mathrm{N}, 100^{\circ} \mathrm{E}\right.$; GAIA co-ordinates) near Chumphon in Thailand 
the Pearson correlation coefficient of the peak PRE with (a) electron density, (b) eastward current density, and (c) eastward neutral wind during the equinoctial months of March, April, September and October at the altitudes of 100-600 km for the years 2011 (red line), 2012 (blue line) and 2013 (green line). In Fig. 3a, it is observed that the electron density in the E-region (at altitudes of 100$150 \mathrm{~km}$ ) shows negative correlation with the peak PRE, and the correlation coefficients are approximately -0.4 for $2011,-0.2$ to -0.6 for 2012 and -0.3 to -0.4 for 2013. The electron density in the F-region (at altitudes of $300-450 \mathrm{~km}$ ) also show negative correlation with the peak PRE with maximum negative cross-correlation coefficients of approximately -0.5 for 2011 and 2013 and -0.6 for 2012. The eastward current density correlation coefficient ranges between -0.3 and 0.4 approximately in the E-region $(100-150 \mathrm{~km})$ for all the years $(2011-2013)$ and positive correlation ( 0 to 0.6 ) above $250 \mathrm{~km}$ altitude (Fig. 3b). The cross-correlation coefficient shows two positive peaks. One is seen around $150-160 \mathrm{~km}$ altitudes, and the correlation coefficients are approximately 0.6 during 2011 and 2012, and 0.2 in 2013. The other is around $350-450 \mathrm{~km}$ altitudes, and the cross-correlation coefficients are approximately 0.6 for 2011 and 2012, and 0.4 for 2013. In the F-region, the Pederson current flows in the same direction as the electric field (leading to the positive correlation). Thus, increase in eastward electric field intensifies the Pederson current. The dayto-day variation of current density may be primarily controlled by the electric field. However, the less correlation coefficient values in both E- and F-region in 2013 is not known. As shown in Fig. 3c, the cross-correlation coefficients between the peak PRE and eastward neutral wind are between -0.2 and 0.2 below $150 \mathrm{~km}$ altitude for all the years (2011-2013). Above $300 \mathrm{~km}$ altitude, the crosscorrelation coefficient is approximately 0.4 and does not show altitude dependence (nearly constant). This could be because the neutral wind does not change largely with altitude due to high viscosity in the F-region (Yerg 1955).

Figure 4 portrays day-to-day variations of peak PRE with ( $a, b)$ electron density, (c, d) eastward current density, and (e, f) eastward neutral wind at an altitudes at (top) $1700 \mathrm{LT}$ and (bottom) $1500 \mathrm{LT}$ in an altitude range of $100-600 \mathrm{~km}$ (left Y-axis; contour plot) over $\left(10^{\circ} \mathrm{N}\right.$, $100^{\circ} \mathrm{E}$ ) near Chumphon during the equinoctial months of March and April 2012. The electron density in the F-region is lower at $1500 \mathrm{LT}$ than $1700 \mathrm{LT}$. The negative correlation between the peak PRE and electron density, which can be seen at the time of PRE, is not seen at 1500 LT. Regarding the day-to-day variation of eastward current density around $110 \mathrm{~km}$, that is EEJ, intensity of EEJ enhances intermittently (Fig. 4c, d). Enhancement of EEJ intensity coincide well with increase of peak PRE. It is noted that the magnitude of the current density for EEJ increases up to $2.0 \mathrm{Am}^{-2}$ at $1500 \mathrm{LT}$ and up to $0.7 \mathrm{Am}^{-2}$ at $1700 \mathrm{LT}$ (Fig. 4c). The current density of EEJ decreases with time because the electron density in the E-region decreases rapidly at sunset. Figure $4 \mathrm{e}, \mathrm{f}$ displays the dayto-day variation of eastward neutral wind at altitudes of $100-600 \mathrm{~km}$ and peak PRE over $\left(10^{\circ} \mathrm{N}, 100^{\circ} \mathrm{E}\right)$. Correlation between the neutral wind and peak PRE at 1500 and $1700 \mathrm{LT}$ is not discernible although the correlation is significant at the time of the peak PRE.

Figure 5 represents the cross-correlation coefficient of the peak PRE with (a) electron density, (b) eastward current density and (c) eastward neutral wind at altitudes of

Correlation between Peak PRE and Electron density, Eastward Current density and Eastward Neutral wind over $\left(10^{\circ} \mathrm{N}, 100^{\circ} \mathrm{E}\right)$
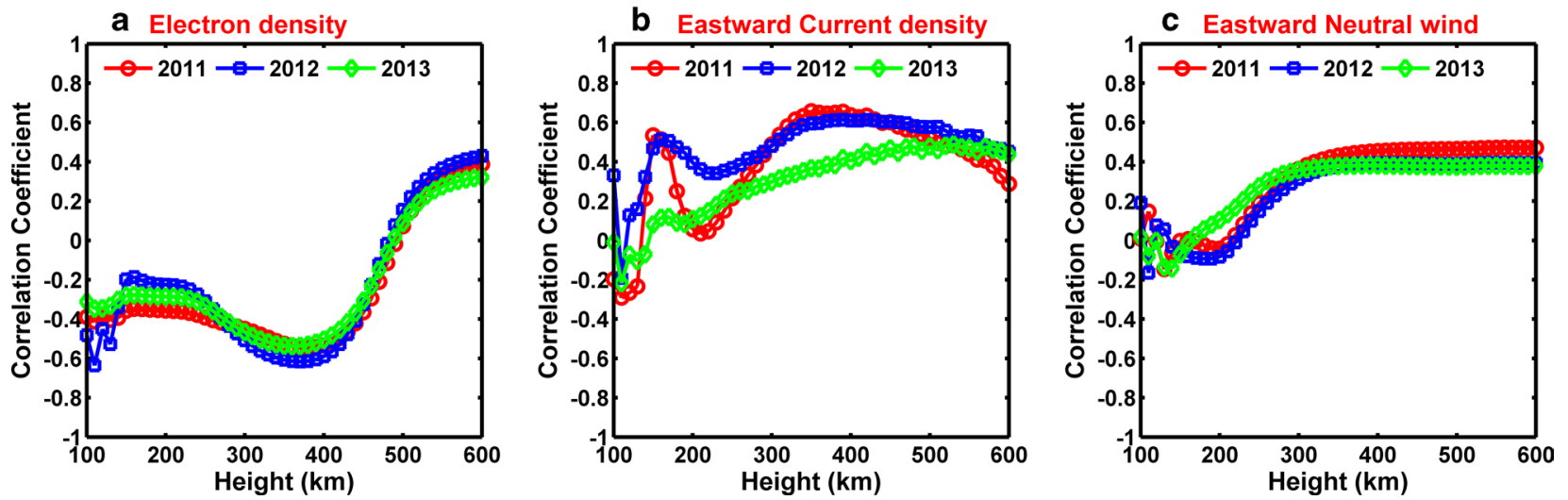

Fig. 3 Correlation between the day-to-day variation of the peak PRE and electron density, eastward current density and eastward neutral wind during 2011 (red line), 2012 (blue line) and 2013 (green line) over (10 N, 100 E; GAIA co-ordinates) near Chumphon in Thailand 

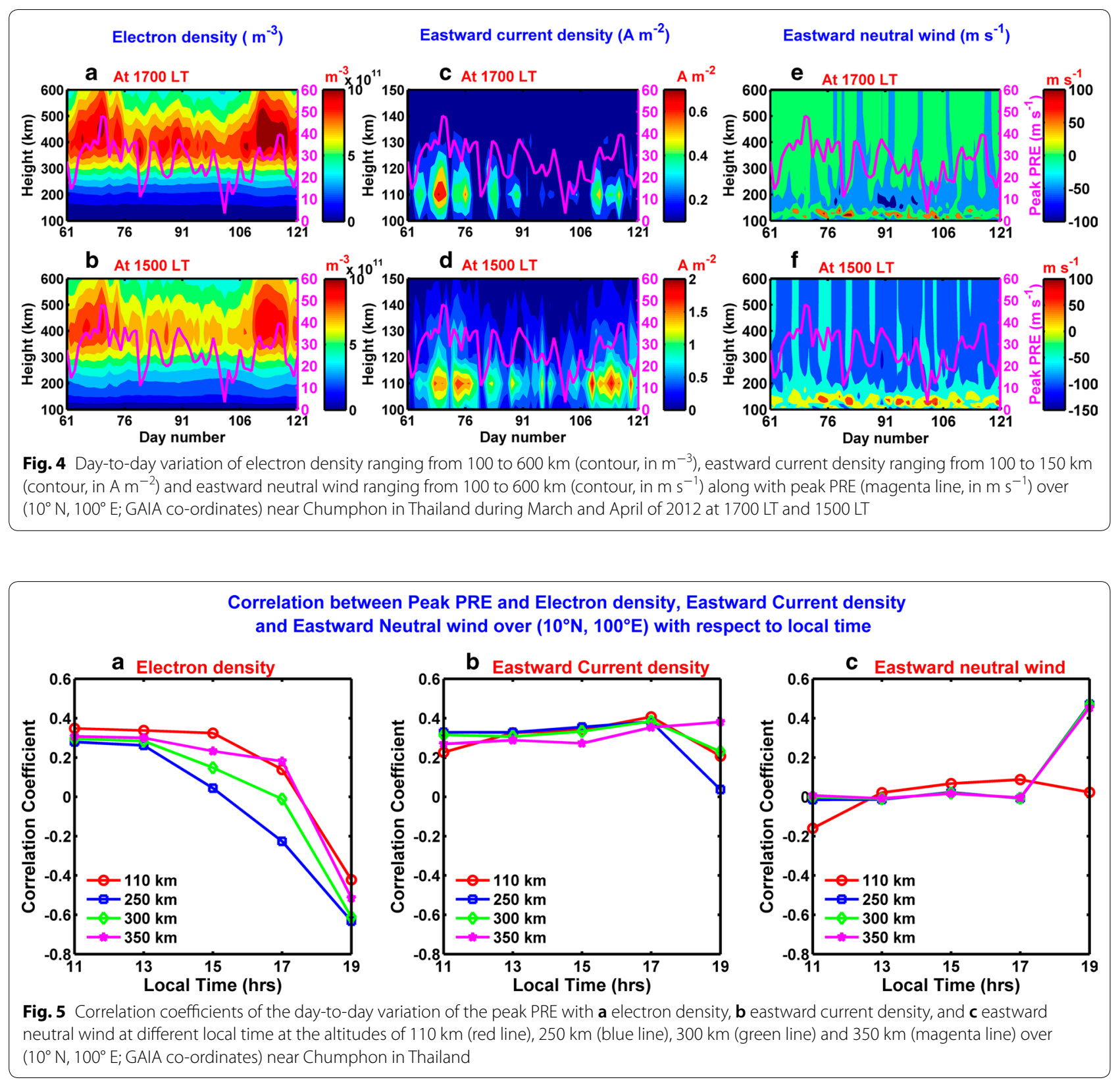

$110 \mathrm{~km}, 250 \mathrm{~km}, 300 \mathrm{~km}$ and $350 \mathrm{~km}$ at different local time (1100 LT, $1300 \mathrm{LT}, 1500 \mathrm{LT}, 1700 \mathrm{LT}$ and $1900 \mathrm{LT}$ ) over the magnetic equator during the equinoctial months of 2011-2013. In case of plasma density, the correlation coefficient goes on decreasing from 1100 LT (around 0.3 ) to $1900 \mathrm{LT}$ (ranging from -0.4 to -0.6 for different altitudes). The cross-correlation coefficients with eastward current density increases with local time from approximately $0.2-0.35$ at $1100 \mathrm{LT}$ to 0.4 at $1700 \mathrm{LT}$. The maximum correlation coefficient value of 0.4 is obtained at $1700 \mathrm{LT}$ for all the altitudes $110 \mathrm{~km}, 250 \mathrm{~km}, 300 \mathrm{~km}$ and $350 \mathrm{~km}$. Therefore, it is observed that the pre-sunset (at $1700 \mathrm{LT}$ ) eastward current density can predict the generation of PRE in GAIA as the peak PRE is observed around 1830 to 1900 LT mostly. In case of neutral wind, the maximum correlation is seen in the F-region (250, 300 and $350 \mathrm{~km}$ ) with maximum correlation coefficient of 0.5 at $1900 \mathrm{LT}$.

Figure 6 displays the scatter plot showing the correlation of eastward current density at 1700 LT versus the peak PRE (during the equinoctial months of 2011-2013) at the altitude of $110 \mathrm{~km}$ over $\left(10^{\circ} \mathrm{N}, 100^{\circ} \mathrm{E}\right.$; GAIA coordinates) near Chumphon in Thailand. It is found that the peak PRE and eastward current density depicts a 


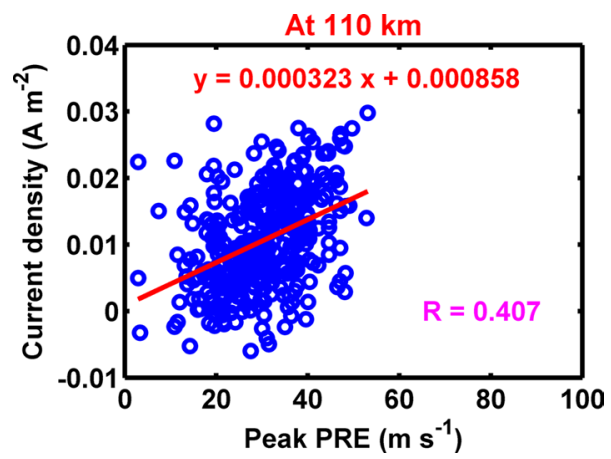

Fig. 6 Scatter plot showing the correlation of eastward current density around 1700 LT versus the peak PRE (during the equinoctial months of 2011-2013) at the altitude of $110 \mathrm{~km}$ over $\left(10^{\circ} \mathrm{N}, 100^{\circ} \mathrm{E}\right.$; GAIA co-ordinates) near Chumphon in Thailand

positive correlation with correlation coefficient (R) of 0.407 .

\section{Discussion}

We have investigated cross-correlations between dayto-day variation of the peak PRE and that of the electron density, eastward current density and eastward neutral wind, and found the followings: (1) F-region winds at the time of the peak PRE is positively correlated with the peak PRE. The cross-correlation coefficient is 0.5. (2) The eastward current density at an altitude of $110 \mathrm{~km}$ has positive correlation with peak PRE. Their cross-correlation coefficient is approximately 0.4 at $1700 \mathrm{LT}$. (3) The electron density in the F-region shows negative correlation with peak PRE. Below, the possible mechanisms of PRE and its relationship with the above parameters will be discussed.

The eastward neutral winds in the F-region (250, 300 and $350 \mathrm{~km}$ ) show significant correlation with the peak PRE with correlation coefficient of 0.5 (approximately) at 1900 LT while the eastward electric current depicts correlation coefficient of 0.4 (approximately) at $1700 \mathrm{LT}$ (presunset). According to Farley et al. (1986), mechanism for generating PRE is explained below. The neutral wind in the F-region $(\boldsymbol{U})$ blows eastward at the evening terminator because the neutral winds in the F-region is driven by the pressure gradient of the neutral atmosphere due to the solar heating. Due to the $\boldsymbol{U}$, which blows across the geomagnetic field $(\boldsymbol{B})$, downward polarization electric field $\left(\boldsymbol{E}_{\phi}\right)$, which is in the direction of $-\boldsymbol{U} \times \boldsymbol{B}$, is generated through the F-region dynamo mechanism (Rishbeth 1971). $\boldsymbol{E}_{\phi}$ maps along $\boldsymbol{B}$ to the E-region. In the E-region, $\boldsymbol{E}_{\phi}$ has an equatorward component so that it induces a westward Hall current. The Hall current flows in the dayside because of high conductivity, but it does not flow in the nightside because the plasma density in the E-region disappears rapidly after the sunset. Due to the discontinuity of the Hall current at the evening terminator, negative charges are accumulated at the evening terminator. Consequently, eastward and westward electric fields are generated in the dayside and nightside, respectively. These electric fields are transmitted to the F-region. The eastward electric field in the dayside corresponds to PRE. Considering this mechanism, it is expected that the peak PRE could be intense when $\boldsymbol{U}$ is intense. The intense eastward electric fields make the growth rate of the RTI large, and thus EPB likely occurs. Otsuka et al. (2006) has pointed out close relationship between the eastward drift velocity and EPB occurrence. Their observations show that EPB occurrence rate is higher in March equinox than September equinox, and that the eastward plasma drift velocity (downward electric field) is larger in March equinox than September equinox. They have studied relationship between the downward electric field and $\mathrm{EPB}$ occurrence at the basis of seasonal variation. Our study suggest that the eastward neutral wind, which drive the downward electric field through the F-region dynamo mechanism, is closely related to the peak PRE, and that this scenario is applicable to their day-to-day variations. In this study, we have also investigated contribution of the zonal winds in the E-region on PRE because the E-region winds drive Hall current, which is not considered in the theory of Farley et al. (1986). Our results show that the E-region winds over magnetic equator have very less correlation with PRE. On the other hand, using WACCM-X model, Liu (2020) has shown that the day-today variation of PRE over the July period, when PRE is weak, is strongly affected by the large-scale lower atmosphere variability through the E-region dynamo at middle latitudes in the summer hemisphere. These results suggest that the PRE may be controlled by global distribution of electric fields.

GAIA model has shown negative correlation between the peak PRE and electron density in the F-region at magnetic equator. The eastward electric field of PRE elevates the F-region plasma at the magnetic equator to higher altitudes by $\mathrm{E} \times \mathrm{B}$ drift. The plasma moves down along the magnetic field lines under the influence of gravitational forces. This phenomenon is known as the "equatorial fountain". This fountain effect causes plasma density depression or trough at the magnetic equator fringed by two nearly symmetric crests at conjugate low magnetic latitudes $\left( \pm 15^{\circ}\right)$, characterizing the equatorial ionization anomaly (EIA) (Moffett and Hanson 1965). Consequently, negative correlation between the PRE and F-region electron density over the magnetic equator represents the trough of plasma density caused by the equatorial fountain. When PRE is intense, the F-region electron density decreases at the magnetic equator. 
GAIA model has succeeded in reproducing EEJ, which is an intense electro jet flowing at an altitude of approximately $100 \mathrm{~km}$ during daytime. GAIA model shows that EEJ is correlated with the peak PRE with cross-correlation coefficient of approximately 0.4 at $1700 \mathrm{LT}$ and approximately 0.3 at $1100 \mathrm{LT}$. It should be noted that the PRE occurs between 1830 and 1900 LT. Therefore, EEJ can be utilized to predict the probable development of PRE observationally. Uemoto et al. (2010) have compared EEJ with the PRE strength and the onset of ESF over Chumphon during a period from November 2007 to October 2008, and shown that EEJ 1-2 h prior to sunset is positively correlated with PRE strength and spread-F occurrence. This led them to conclude that the pre-sunset E-region dynamo and/or electric field can be related to the F-region dynamics and onset of ESF around sunset. The present results show that GAIA reproduced well the relationship between the EEJ and PRE.

\section{Summary and conclusions}

Using an atmosphere-ionosphere coupled model (GAIA), we have studied what parameter mainly controls day-to-day variation of PRE. We have compared day-to-day variations of the peak PRE with electron density, eastward current density and eastward neutral wind over magnetic equator at $\left(10^{\circ} \mathrm{N}, 100^{\circ} \mathrm{E}\right)$ near Chumphon, Thailand during the equinoctial months (March, April, September and October) in 2011-2013 during a high solar activity period. The important findings in this study are described as follows:

1. The F-region winds (at altitudes of $250-350 \mathrm{~km}$ ) are positively correlated with the peak PRE, and their cross-correlation coefficient is approximately 0.4 when the PRE reaches a peak. This result indicates that the F-region winds control the peak PRE through the mechanisms of the F-region dynamo and PRE including E- and F-region coupling processes. On the other hand, correlation of E-region winds with the peak PRE is not seen.

2. The eastward current density at an altitude of $110 \mathrm{~km}$ during daytime, which is EEJ, has positive correlation with peak PRE. The cross-correlation coefficient between the current density and peak PRE increases with time until pre-sunset, and is approximately 0.4 at $1700 \mathrm{LT}$. This result is consistent with the previous observations. It should be noted that the EEJ strength can be used to predict magnitude of the PRE a few hours prior to the sunset.

3. The electron density in the F-region shows negative correlation with peak PRE. This could be due to transport of the plasma density to the low latitudes by 'fountain effect' which is responsible for the EIA.
The present study shows electro-dynamical forces coupled between E- and F-region could play an important role in day-to-day variation of the peak PRE.

\section{Abbreviations \\ EEJ: Equatorial electro jet; EIA: Equatorial ionization anomaly; EPB: Equato- rial plasma bubble; ESF: Equatorial Spread-F; EUV: Extreme ultraviolet; GAIA: Ground-to-topside model of atmosphere-ionosphere for aeronomy; LT: Local time; PRE: Pre-reversal enhancement; RTI: Rayleigh-Taylor instability; TIEGCM: Thermosphere/ionosphere/electrodynamic general circulation model.}

\section{Acknowledgements}

Simulations and data analyses in this work were performed using Hitachi SR16000/M1 and the NICT Science Cloud System, Japan. The authors duly acknowledge the reviewers for their valuable comments.

\section{Authors' contributions}

PG carried out the data analysis and wrote the manuscript. YO conceived the idea, involved in elucidation of data analysis and organization of the paper. SM was engaged in the data interpretation. $\mathrm{HS}$ participated in reviewing the paper and is responsible person for GAIA model simulations. All authors read and approved the final manuscript.

\section{Funding}

The present study was supported by the Japan Society for the Promotion of Science, KAKENHI (15H05815), Project for Solar-Terrestrial Environment Prediction (PSTEP).

\section{Availability of data and materials}

To access the GAIA simulation data, contact H. Jin (jin@nict.go.jp).

\section{Ethics approval and consent to participate}

Not applicable.

\section{Consent for publication \\ Not applicable.}

\section{Competing interests}

The authors declare that they have no competing interests.

\section{Author details}

${ }^{1}$ Institute for Space-Earth Environmental Research, Nagoya University, Nagoya 464-8601, Japan. ${ }^{2}$ National Institute of Information and Communications Technology, Koganei, Tokyo 184-8795, Japan.

Received: 22 April 2020 Accepted: 30 June 2020

Published online: 06 July 2020

\footnotetext{
References

Abadi P, Otsuka Y, Tsugawa T (2015) Effects of pre-reversal enhancement of $E \times B$ drift on the latitudinal extension of plasma bubble in southeast asia international CAWSES-II symposium. Earth Planets Space. https://doi. org/10.1186/s40623-015-0246-7

Abdu MA (2001) Outstanding problems in the equatorial ionosphere- - thermosphere electrodynamics relevant to spread F. J Atmos Solar-Terrestrial Phys 63:869-884. https://doi.org/10.1016/S1364-6826(00)00201-7

Abdu MA, de Medeiros RT, Bittencourt JA, Batista IS (1983) Vertical ionization drift velocities and range spread $F$ in the evening equatorial ionosphere. J Geophys Res Sp Phys 88:399-402. https://doi.org/10.1029/JA088iA01p 00399

Dabas RS, Singh L, Lakshmi DR, Subramanyam P, Chopra P, Garg SC (2003) Evolution and dynamics of equatorial plasma bubbles: relationships to ExB drift, postsunset total electron content enhancements, and equatorial electrojet strength. Radio Sci 38(4):1075. https://doi.org/10.1029/2001R S002586
} 
Farley DT, Bonelli E, Fejer BG, Larsen MF (1986) The prereversal enhancement of the zonal electric field in the equatorial ionosphere. J Geophys Res Sp Phys 91:13723-13728. https://doi.org/10.1029/JA091iA12p13723

Fesen CG, Crowley G, Robie RG, Richmond AD, Fejer BG (2000) Simulation of the pre-reversal enhancement in the low latitude vertical ion drifts. Geophys Res Lett 27:1851-1854. https://doi.org/10.1029/2000GL000061

Huang CS (2018) Effects of the postsunset vertical plasma drift on the generation of equatorial spread F. Prog Earth Planet Sci. https://doi.org/10.1186/ s40645-017-0155-4

Huang C, Hairston MR (2015) The postsunset vertical plasma drift and its effects on the generation of equatorial plasma bubbles observed by the C/NOFS satellite. J Geophys Res Sp Phys 120:2263-2275. https://doi. org/10.1002/2014JA020735

Jin H, Miyoshi Y, Fujiwara H et al (2011) Vertical connection from the tropospheric activities to the ionospheric longitudinal structure simulated by a new Earth's whole atmosphere-ionosphere coupled model. J Geophys Res 116:1-9. https://doi.org/10.1029/2010JA015925

Liu HL (2020) Day-to-day variability of prereversal enhancement in the vertical ion drift in response to large-scale forcing from the lower atmosphere. Sp Weather. https://doi.org/10.1029/2019SW002334

Moffett RJ, Hanson WB (1965) Effect of ionization transport on the equatorial F-region. Nature 206:705-706. https://doi.org/10.1038/206705a0

Otsuka Y, Shiokawa K, Ogawa T (2006) Equatorial ionospheric scintillations and zonal irregularity drifts observed with closely-spaced GPS receivers in Indonesia. J Meteorol Soc Jpn 84:343-351. https://doi.org/10.2151/ jmsj.84A.343
Rishbeth $H$ (1971) Polarization fields produced by winds in the equatorial F-region. Planet Sp Sci 19:357-369. https://doi.org/10.1016/00320633(71)90098-5

Shinagawa H, Jin H, Miyoshi Y et al (2018) Daily and seasonal variations in the linear growth rate of the Rayleigh-Taylor instability in the ionosphere obtained with GAIA. Prog Earth Planet Sci 5:16. https://doi.org/10.1186/ s40645-018-0175-8

Sultan PJ (1996) Linear theory and modeling of the Rayleigh-Taylor instability leading to the occurrence of equatorial spread F. J Geophys Res Sp Phys 101:26875-26891. https://doi.org/10.1029/96JA00682

Tulasi Ram S, Rama Rao PVS, Niranjan K et al (2006) The role of post-sunset vertical drifts at the equator in predicting the onset of VHF scintillations during high and low sunspot activity years. Ann Geophys 24:1609-1616. https://doi.org/10.5194/angeo-24-1609-2006

Uemoto J, Maruyama T, Saito S et al (2010) Relationships between pre-sunset electrojet strength, pre-reversal enhancement and equatorial spreadF onset. Ann Geophys 28:449-454. https://doi.org/10.5194/angeo $-28-449-2010$

Yerg DG (1955) Viscosity in the high atmosphere. J Geophys Res Sp Phys 60:87-94. https://doi.org/10.1029/JZ060i001p00087

\section{Publisher's Note}

Springer Nature remains neutral with regard to jurisdictional claims in published maps and institutional affiliations.

\section{Submit your manuscript to a SpringerOpen ${ }^{\circ}$ journal and benefit from:}

- Convenient online submission

- Rigorous peer review

- Open access: articles freely available online

- High visibility within the field

- Retaining the copyright to your article

Submit your next manuscript at springeropen.com 